\title{
The utility of the polymerase chain reaction assay for aetiologic definition of unspecified bacterial meningitis cases
}

\author{
Mari Tuyama/', Renata F Boente, Maria C Rebelo², Ricardo P Igreja', David E Barroso/ ${ }^{+}$ \\ Laboratório de Enterovírus, Grupo de Doenças Virais, Rickettsioses e Febres Hemorrágicas, Instituto Oswaldo Cruz-Fiocruz, Av. Brasil \\ 4365, 21040-900 Rio de Janeiro, RJ, Brasil 'Serviço de Doenças Infecciosas e Parasitárias, Hospital Universitário Clementino Fraga Filho, \\ Universidade Federal do Rio de Janeiro, Rio de Janeiro, RJ, Brasil ${ }^{2}$ Laboratório de Referência Estadual para Meningites, \\ Instituto Estadual de Infectologia São Sebastião, Rio de Janeiro, RJ, Brasil
}

\begin{abstract}
Most patients with acute suppurative meningitis are otherwise healthy individuals with regard to immune mechanisms against invasive bacterial disease. This medical emergency is among the most dramatic and potentially ravaging diseases that affect humans, particularly young children. The illness often strikes suddenly, and can either result in death or leave the survivors with significant neurological dysfunctions. The demonstration of a bacterial aetiology is necessary for decisions regarding treatment and prophylaxis. Conventional bacteriological methods frequently fail to identify an agent, as a result of administration of antibiotics or delayed lumbar punctures. We investigated the major aetiologic sources of unspecified bacterial meningitis cases (G00.9, ISCD-10) by polymerase chain reaction $(P C R)$-based identification of Neisseria meningitidis (crgA), Streptococcus pneumoniae (ply) and Haemophilus influenzae (bexA) in cerebrospinal fluid samples. The multiplex PCR detected $\mathrm{N}$. meningitidis in $92 \%$, S. pneumoniae in 4\% and $\mathrm{H}$. influenzae in $1 \%$ of the 192 clinical samples assayed; 3\% were negative for all three DNA targets. Bacterial DNA detection was found to be a valuable adjunct to enhance bacterial meningitis surveillance when the yield of specimens by culture is reduced. The implementation of PCR assays as a diagnostic procedure in Public Health Laboratories is perceived to be a significant advance in the investigation of bacterial meningitis.
\end{abstract}

Key words: meningitis - PCR - Streptococcus pneumoniae - Neisseria meningitidis - Haemophilus influenzae - cerebrospinal fluid

Despite the advent of glycoprotein conjugate vaccines and the development of new antimicrobial agents, bacterial infections of the central nervous system continue to pose a serious threat to the health and welfare of people world-wide (Finn 2004, Harrison 2006), particularly in developing nations (Greenwood 2000, Chanteau et al. 2006, Pedro et al. 2007). At least 1.2 million cases of bacterial meningitis are estimated to occur each year, and 135,000 of these patients die (WHO 1998). The disease can affect any age group, but the young are the most vulnerable; the highest age specific attack rates are seen in infancy. The most common meningeal bacteria, Neisseria meningitidis, Streptococcus pneumoniae, and Haemophilus influenzae, account for $90 \%$ of confirmed cases around the world (WHO 1998, Stephens 2007). Bacteria other than those three are isolated mostly from the cerebrospinal fluid (CSF) of new-born patients, normally in the context of septicaemia, or in subjects with a wide variety of immunosuppressive diseases or congenital defects, e.g., occipital or lumbar dermal sinuses, or intraventricular shunts (Greenwood 2000).

The epidemiology and frequency of the different aetiologies of bacterial meningitis has changed over the last century. An unexplained increased incidence of $H$.

Finnancial support: Faperj (2006.0329.7)

+ Corresponding author: barroso@ioc.fiocruz.br

Received 26 April 2007

Accepted 27 February 2008 influenzae type b (Hib) meningitis cases was observed in the 1930s, and over the years it became one of the most common causes of meningitis in children up to 5-years old (Fothergill \& Sweet 1933). This bacterium is now a rare human pathogen in regions where the Hib conjugate vaccine was introduced in childhood immunization programs (Finn 2004). Reports published in the first decades of the XX century emphasized the strong association of $S$. pneumoniae meningitis with lobar pneumonia (Dunn 1911). However, currently it occurs most often as a complication of suppurative paracranial infections, of systemic sepsis, of skull trauma with CSF leak, or secondary to conditions with defective clearance of pneumococcal bacteremia or antibody formation (Greenwood 2000). In the past, $N$. meningitidis was best known as a cause of massive epidemics, incidence 100-1,000/100,000 population, in civilians and in the context of prolonged military deployment (North 1980). At present, during epidemic waves of disease, the reported incidence increases, but seldom reaches more than $10-20$ cases per 100,000 population, except in the African continent (Wylie et al. 1997, WHO 1998). Also, this organism retains its ability to cause endemic or hyperendemic (1-10/100,000 population) life-threatening disease in the form of septicaemia or meningitis (Riordan 2001, Stephens 2007).

Bacterial meningitis surveillance constitutes one of the major activities of consultants in communicable disease control in the state of Rio de Janeiro, in the Southeast of Brazil. However, laboratories have only been instrumental in identifying meningeal pathogens since 1974, when a large epidemic of meningococcal disease 
motivated the Brazilian Ministry of Health to structure the epidemiological surveillance of meningitis and the role of the laboratory in analyses of infections of the central nervous system (DMEG 1974). At that time, laboratory techniques used in the isolation and identification of bacteria from the CSF of patients with clinical meningitis were implemented in the Infectious Diseases State Institute São Sebastião (IEISS), in the city of Rio de Janeiro. Conventional bacteriology has been used with poor results for case ascertainment during the last ten years, mainly due to the practice of administering antibiotics before admission and reluctance to performance lumbar punctures at presentation (Pedro et al. 2007). The absence of an adjunct laboratory technique for detection of non-culturable bacteria has resulted in a great number of notifications of non-culture proven (unspecified) meningitis cases without a rash, with CSF white blood cell count compatible with pyogenic bacterial infection (Fig. 1).

In the years 2001 to 2005, the Rio de Janeiro State Department of Health (RJSDH) received the notification of 4,555 cases of suppurative bacterial meningitis with a lethality of $21 \% ; 3,129(69 \%)$ of those cases were not aetiologically identified by traditional laboratory methods (culture or direct smear or antigen detection); 1,596 were unspecified bacterial meningitis cases (G00.9, ISCD-10) and 1,533 were suspected meningococcal disease cases (A39.9, ISCD-10), and the proportions of cases resulting in death were $14 \%$ and $24 \%$, respectively. In the same period, 578 cases of meningococcal disease (A39.0+G01* or A39.2, ISCD-10), 772 cases of S. pneumoniae (G00.1, ISCD-10) and 76 cases of $H$. influenzae (G00.0, ISCD-10) meningitis were recorded with the causative organisms demonstrated by currently used laboratory techniques; case-fatality rates were $16 \%$, $34 \%$, and $14 \%$, respectively. The great majority of these cases were from the Rio de Janeiro Metropolitan area. In this study, we present the utility of a multiplex polymerase chain reaction (PCR) assay for the definition of the most common aetiologic sources of bacterial meningitis in unspecified cases.

\section{PATIENTS, MATERIALS AND METHODS}

The study was reviewed and approved by the Ethics Committee of Hospital Evandro Chagas Clinical Research Institute-Fiocruz, Rio de Janeiro. Between 2004 and 2006, fresh CSF samples received for diagnostic purposes at the Meningitis Reference Unit(MRU), associated with the IEISS, were submitted to visual inspection, culture (heated blood agar), latex agglutination test, Gram stain, white blood cell count (total and differential) and measurement of chemical constituents. Generally, there was no description about the conditions of transport of the samples; we believe they were mostly carried at room temperature. Gram stain, culture and antigen detection were negative for all 229 CSF samples collected from patients with suppurative bacterial meningitis (WBC count $\geq 500$ per $\mathrm{mm}^{3} ; \geq 50 \%$ neutrophils) without a nonblanching rash. The CSF samples available from these patients undiagnosed by conventional bacteriological methods, and stored at $-20^{\circ} \mathrm{C}$, were retrospectively enrolled in this study.

An aliquot (not less than $200 \mu \mathrm{l}$ ) from each of 192 (84\%) CSF specimens were transported (on dry ice or chilly pad) to the Instituto Oswaldo Cruz (IOC) for nonculture PCR-based diagnosis of the major aetiologies of bacterial meningitis. Information regarding clinical and laboratory data were recorded for each sample delivered. Bacterial DNA was isolated from the CSF samples with the use of QIAmp DNA Mini Kit (QIAGEN) according to the manufacturer's protocol for DNA purification from Gram-positive bacteria. PCR identification of

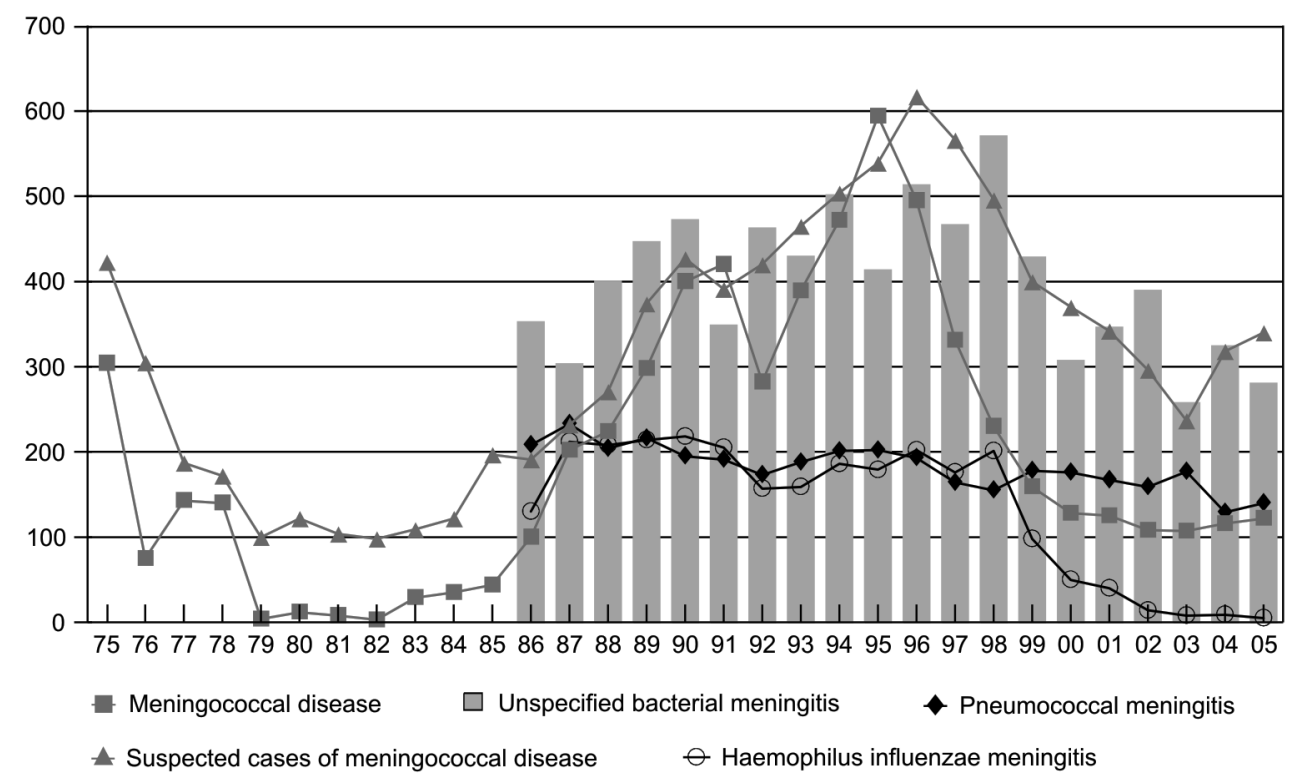

Fig. 1: major aetiologic sources of bacterial meningitis, suspected meningococcal disease, and unspecified bacterial meningitis cases diagnosed in the state of Rio de Janeiro between 1975 and 2005. 
N. meningitidis, S. pneumoniae and H. influenzae (capsulated) was based on a multiplex assay for the amplification of the $\operatorname{crg} A$, ply and bexA genes, respectively, with specific oligonucleotide primers as previously described (van Ketel et al. 1990, Taha 2000, Corless et al. 2001). In a further experiment, all the CSF samples that gave negative results in the first round of multiplex PCR were subjected to PCR with a primer set selected by van Ketel et al. (1990) from the DNA sequence of a gene ( $\mathrm{pal}$ ) encoding for outer-membrane protein P6 (Deich et al. 1988), which can detect any spontaneous capsule-deficient mutants of serotype b (b-) or non-capsulate (NC) strains of $H$. influenzae. However, this primer set does not distinguish between $\mathrm{b}$ - and NC strains.

PCR reaction mixtures $(50 \mu \mathrm{l})$ contained $0.6 \mu \mathrm{M}$ of each oligonucleotide primer (Invitrogen), $200 \mu \mathrm{M}$ dNTPs, 1X PCR buffer, $3 \mathrm{mM} \mathrm{MgCl}$, 1 U Platinun Taq DNA polymerase (Invitrogen), and $10 \mu 1$ of DNA target. PCR parameters were $94^{\circ} \mathrm{C}$ for $3 \mathrm{~min}, 55^{\circ} \mathrm{C}$ for $30 \mathrm{~s}$, and $72^{\circ} \mathrm{C}$ for $20 \mathrm{~s}$, followed by 35 cycles of $92^{\circ} \mathrm{C}$ for $40 \mathrm{~s}$, $55^{\circ} \mathrm{C}$ for $30 \mathrm{~s}, 72^{\circ} \mathrm{C}$ for $20 \mathrm{~s}$, and $72^{\circ} \mathrm{C}$ for $10 \mathrm{~min}$, then holding at $4^{\circ} \mathrm{C}$, in a GeneAmp PCR System 9700 (PE Applied Biosystems), with resolution of amplification products $(10 \mu \mathrm{l})$ on standard $2 \%(\mathrm{wt} / \mathrm{vl})$ agarose gels and visualisation under UV fluorescence by staining with ethidium bromide (Fig. 2). Fragment sizes of amplicons were compared with those of a positive control ampli-

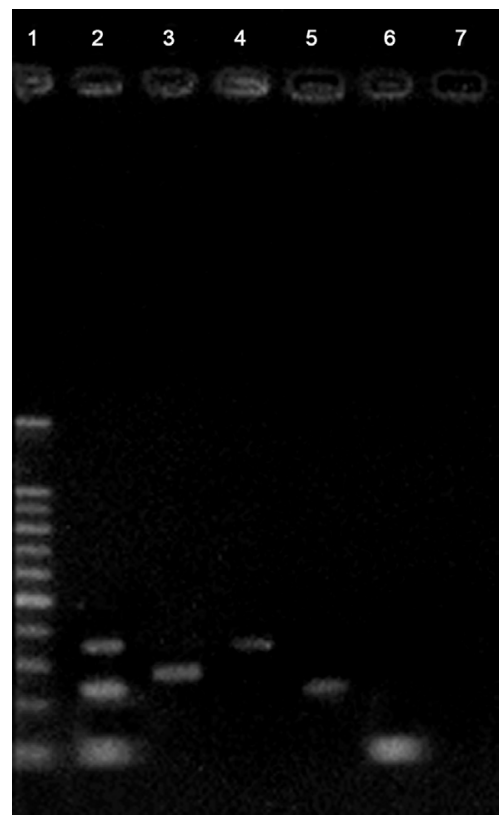

Fig. 2: polymerase chain reaction amplification of the $\operatorname{bexA}, \operatorname{crg} A$, ply and pal genes from reference strains and from cerebrospinal fluid samples from unspecified bacterial meningitis patients. 1: $100 \mathrm{bp}$ molecular mass marker ladder (Promega); 2: Multiplex PCR amplification of the bexA (343 bp), $\operatorname{crg} A(230 \mathrm{bp})$ and ply ( $80 \mathrm{bp})$ genes from standard Haemophilus influenzae ATCC 10211, Neisseria meningitidis ATCC 13090 and Streptococcus pneumoniae ATCC 49619 strains, respectively; 3-6: PCR amplification of the pal (273 bp) gene from a reference $H$. influenzae strain (ATCC 49766) and results obtained when the multiplex PCR was applied to clinical specimens, showing detection of the $\operatorname{crg} A$, bexA and ply genes; 7: negative control. fied product and a $100 \mathrm{bp}$ DNA ladder (Promega) as a molecular weight marker. DNA from standard strains (N. meningitidis ATCC 13,090, S. pneumoniae ATCC 49,619, H. influenzae ATCC 10,211, and H. influenzae ATCC 49,766) was included in each assay as positive controls. Negative controls consisted of reaction mixture without DNA target.

\section{RESULTS}

Within the study period, 192 patients with a clinical scenario suggestive of bacterial meningitis and an absolute diagnosis established by examination of the CSF (WBC count $\geq 500$ per $\mathrm{mm}^{3} ; \geq 50 \%$ neutrophils) were investigated by PCR. Of the total, $36 \%$ were 5 -years old or younger, and the median age was 17 years (range, 13 days to 73 years). The proportion of male and female patients was $63 \%$ and $37 \%$, respectively. Visual inspection of CSF samples distinguished the following categories: cloudy $(87 \%)$, purulent $(3 \%)$, and haemorrhagic $(10 \%)$. The mean of CSF white blood cell count was $4,525 / \mathrm{mm}^{3}$ (range, 500 to $30,000 / \mathrm{mm}^{3}$ ); the differential of white blood cells was $57 \%$ to $100 \%$ of neutrophils.

The CSF samples were investigated by means of the multiplex PCR protocol at IOC. Amplification of each selected sequence was not affected by the presence of DNA from other bacterial targets (Fig. 2). PCR resolved diagnostic problems in $97 \%$ (187/192) of the samples assayed; the remaining $3 \%$ were negative for all three DNA targets. Of the positive samples, $N$. meningitidis DNA was detected in $92 \%(\mathrm{n}=176)$, S. pneumoniae in $4 \%(\mathrm{n}=$ $8)$, and H. influenzae in $1 \%(\mathrm{n}=3)$. None of the negative samples were positive for the pal gene sequence.

The three PCR positive samples for the presence of the bexA gene were collected from a 1-month old infant and a 20 -year old man with CSF leak due to skull trauma in 2005. Neither patient was likely to have received the Hib conjugate vaccine before hospital admission because of their age. The third patient was a 2-year old boy with no reference of Hib vaccination status. Thus, PCRbased surveillance of unspecified bacterial meningitis without a suggestive rash retrospectively disclosed a meningococcal aetiology in 176 cases, implying that no action was taken at the right time about control measures for their close contacts. Also, patients were discharged without administering chemoprophylaxis recommended for eradication of $N$. meningitidis from the nasopharynx of survivors treated with penicillin or chloramphenicol (Barroso 1999). Chemoprophylaxis retains a limited but important role in preventing secondary spread within households and close contacts outside the immediate family (Barroso et al. 1998).

\section{DISCUSSION}

In vitro enzymatic synthesis to amplify specific DNA sequences by PCR has proven to be a valuable technology for diagnostic microbiology due to its inherent high sensitivity and specificity. It also has considerable importance for non-culture diagnosis because of its potential to detect DNA from non-culturable bacteria and from microorganisms that grow slowly or cannot be cultivated in vitro. The inception of PCR assays in 1985 was 
followed by reports on a wide variety of applications for PCR in medicine (Stoker 1991, Engleberg \& Eisenstein 1992). Bacterial DNA can be extracted from clinical samples of patients with clinically diagnosed meningitis, and amplified to detect the causative agent by this molecular approach (Clarke 2006). This enables confirmation of the disease-causing organism by the presence of its DNA, which makes it possible to disclose non-viable bacteria obtained from delayed lumbar punctures up to $72 \mathrm{~h}$ after commencement of parenteral antibiotics (Taha \& Olcén 2004, Chanteau et al. 2006, Pedro et al. 2007). More recently, it has been used as a significant adjunct molecular laboratory technique for the demonstration of the most common aetiologies of bacterial meningitis in many Reference Centres (Taha et al. 2005). It has been implemented as a policy for enhanced surveillance and ascertainment to improve treatment of cases and contacts, advise control measures for the community, and monitor vaccine efficacy (Corless et al. 2001, PHLS 2002, Clarke 2006).

Prior to this study, we conducted an assessment of a PCR protocol to detect $N$. meningitidis (crgA) or $S$. pneumoniae (ply) in CSF samples from positive cases collected and transported using local field conditions, by calculating efficiency values (Matos et al. 2006, Rebelo et al. 2006). The sensitivities (as percentages) were $100 \%$ (95\% CI $96-100 \%$ ) and $96 \%$ (95\% CI 90-99\%), respectively; specificity was $100 \%$ when applied for the selected culture isolates from CSF. The small numbers of $H$. influenzae meningitis cases during the last few years hindered the evaluation of the bexA primer set. Nevertheless, in previous reports the sensitivity was high and equivalent to those assessed; the primer set was $100 \%$ specific (van Ketel et al. 1990, Corless et al. 2001). Indeed, outside of the MRU, some specimens may have been stored and transported in suboptimal temperature conditions, which might have affected the sensitivity of the PCR assay. We have used an improved DNA extraction procedure (QIAGEN), which may increase the sensitivity of the assays in this study. Our approach yielded few negative results within the samples assayed (5/192), highlighting the benefits of this sampling technique for solving diagnostic problems. Although less frequently, meningitis may be caused by other species not screened by the PCR assay described here.

The results obtained with the PCR protocol described here revealed that cases of unspecified bacterial meningitis (G00.9, ISCD-10) were mostly caused by $N$. meningitidis $(92 \%)$, compared with results published previously in which the patients $(96 \%)$ had suspected meningococcal disease (Pedro et al. 2007). This might be expected taking into account the prevalence of meningococcal disease and the high susceptibility of the bacteria to antibiotic clearance in the vasculature and CSF (Stephens 2007). Partial antibiotic therapy has considerable effect on recovery of $N$. meningitidis, but not when meningitis is caused by $H$. influenzae (Dalton \& Allison 1968) and, particularly, S. pneumoniae (Feldman 1978, Kanegaye et al. 2001). Besides, the majority of notified cases of meningococcal disease $(73 \% ; 1,533 / 2,111)$ between 2001 and 2005, were based only on clinical observations (clinically diagnosed bacterial meningitis with a suggestive rash or purpura fulminans) accompanied by a high case-fatality rate $(24 \% ; 362 / 1,533)$; an indication of failure to diagnose the less severe cases, such as those without skin manifestation (WHO 1998). Our results, jointly with the local surveillance data shown above, make this assertion plausible, considering that the association of this case-fatality rate as the result of infections with a high virulent strain is questionable. In developing countries, the overall mortality rate of treated patients with meningococcal disease is usually about 10\% (Greenwood 2000, Stephens 2007). The case-fatality rate, according to clinical presentation among 2106 patients admitted to the wards or intensive care unit of the IEISS, was 3\% for meningitis, $9 \%$ for septicaemia and meningitis, and 33\% for septicaemia, over a 7-year period (Barroso et al. 2005).

$N$. meningitidis is the leading cause of communityacquired acute meningitis and septicaemia in all age categories, even before the introduction of Hib glycoprotein conjugate vaccine in the state of Rio de Janeiro in 1999 (RJSDH). We want to point out that the introduction of the Hib conjugate vaccine drastically decreased the occurrence of $H$. influenzae meningitis, but it did not interfere much with the overall prevalence of unspecified bacterial meningitis (Fig. 1). Nevertheless, chemoprophylaxis is not currently recommended for close contacts of non-culture proven meningitis cases. This has serious implications for the prevention of secondary cases as well as case clusters, especially in a school or a day care center environment (Barroso et al. 1998). When a diagnosis cannot be confirmed, the decision to administer chemoprophylaxis should depend on a consultation with the attending physician responsible for the case (PHLS 2002). There is a small but real risk of further linked cases of potentially fatal disease after clinical diagnosis of a meningococcal patient, however this risk also exists for close contacts of $H$. influenzae and, to a lesser extent, S. pneumoniae meningitis patients (Barroso et al. 1998, Razzaq et al. 1998, Barroso 1999, Greenwood 2000). However, the use of antibiotics as prophylactic measures directed to close contacts of an identified case does not completely prevent the possible occurrence of secondary cases and, thus, some degree of medical surveillance remains necessary. These points should be seriously considered because meningococcal vaccines are not readily available for the control of secondary cases and case clusters in Brazil.

The implementation of PCR assays for diagnostic purposes became absolutely essential due to a change in clinical management over the last decade. It is important to point out that fewer lumbar punctures are performed at presentation and prompt antibiotic therapy is advisable in pyrexial patients with a suggestive rash; this has contributed to a significant fall in the number of culture confirmed cases (Wylie et al. 1997, Kanegaye et al. 2001, Riordan 2001, Stephens 2007). The data presented here demonstrate that the non-culture PCR-based diagnosis is a reliable technique with the potential to solve most of the diagnostic problems of patients with acute bacterial meningitis undiagnosed by conventional bac- 
teriological methods. In spite of that, when all diagnostic tests were combined, the number of confirmed cases increased (PHLS 2002, Taha \& Olcén 2004, Matos et al. 2006, Rebelo et al. 2006). The implementation of PCR for diagnostic purposes is of paramount importance for enhanced ascertainment, treatment and control of the disease in our community.

\section{ACKNOWLEDEGMENT}

To Dr. Maria de Fátima Calderaro of the Meningitis Advisory Committee, RJSDH for providing the epidemiological surveillance data.

\section{REFERENCES}

Barroso DE 1999. Neisseria meningitidis nasopharynx colonisation of diseased patients on presentation and on discharge. Trop Doct 29: 108-109.

Barroso DE, de Carvalho DM, Nogueira SA, Solari CA 1998. Meningococcal disease: epidemiology and control of secondary cases. Rev Saude Publica 32: 89-97.

Barroso DE, Pedro LGF, Machado SC 2005. Doença meningocócica. In JR Coura, Dinâmica das Doenças Infecciosas e Parasitárias, Guanabara Koogan, Rio de Janeiro, p. 1449-1469.

Chanteau S, Sidikou F, Djibo S, Moussa A, Mindadou H, Boisier P 2006. Scaling up of PCR-based surveillance of bacterial meningitis in the African meningitis belt: indisputable benefits of multiplex PCR assay in Niger. Trans $R$ Soc Trop Med Hyg 100: 677-680.

Clarke SC 2006. Detection of Neisseria meningitidis, Streptococcus pneumoniae, and Haemophilus influenzae in blood and cerebrospinal fluid using fluorescence-based PCR. In L O'Connor, Diagnostic Bacteriology Protocols, Human Press, Totowa, p. 69-78.

Corless CE, Guiver M, Borrow R, Edwards-Jones V, Fox AJ, Kaczmarski EB 2001. Simultaneous detection of Neisseria meningitidis, Haemophilus influenzae, and Streptococcus pneumoniae in suspected cases of meningitis and septicemia using real-time PCR. J Clin Microbiol 39: 1553-1558.

Dalton HP, Allison MJ 1968. Modification of laboratory results by partial treatment of bacterial meningitis. Am J Clin Pathol 49: 410-413.

Deich RA, Metcalf BJ, Finn CW, Farley JE, Green BA 1988. Cloning of genes encoding a 15000-dalton peptidoglycan-associated outer membrane lipoprotein and an antigenically related 15000-dalton protein from Haemophilus influenzae. J Bacteriol 170: 489-498.

DMEG - Doença Meningocócica no Estado da Guanabara 1974. Bol Epidemiol 6: 171-176.

Dunn CH 1911. Cerebrospinal meningitis, its etiology, diagnosis, prognosis and treatment. Am J Dis Child 1: 95-112.

Engleberg NC, Eisenstein BI 1992. Detection of microbial nucleic acids for diagnostic purposes. Annu Rev Med 43: 147-155.

Feldman WE 1978. Effect of prior antibiotic therapy on concentrations of bacteria in CSF. Am J Dis Child 132: 672-674.

Finn A 2004. Bacterial polysaccharide-protein conjugate vaccines. Br Med Bull 70: 1-14.

Fothergill LD, Sweet LK 1933. Meningitis in infants and children with special reference to age-incidence and bacteriologic diagnosis. J Pediat 2: 696-710.
Greenwood BM 2000. Acute bacterial meningitis. In GT Strickland, Hunter's Tropical Medicine and Emerging Infectious Diseases, WB Saunders, Philadelphia, p. 372-379.

Harrison LH 2006. Vaccine Prevention of Meningococcal Disease: Making Slow Progress. Clin Infect Dis 43: 1395-1397.

Kanegaye JT, Soliemanzadeh P, Bradley JS 2001. Lumbar puncture in pediatric bacterial meningitis: defining the time interval for recovery of cerebrospinal fluid pathogens after parenteral antibiotic pretreatment. Pediatrics 108: 1169-1174.

Matos JA, Madureira DJ, Rebelo MC, Hofer CB, Barroso DE 2006. Diagnosis of Streptococcus pneumoniae meningitis by polymerase chain reaction amplification of the gene for pneumolysin. Mem Inst Oswaldo Cruz 101: 559-563.

North E 1980. Concerning the epidemic of spotted fever in New England. Rev Infect Dis 2: 811-816.

Pedro LGF, Boente RF, Madureira DJ, Matos JA, Rebelo MC, Igreja RP, Barroso DE 2007. Diagnosis of meningococcal meningitis in Brazil by use of PCR. Scand J Infect Dis 39: 28-32.

PHLS - Public Health Medicine Environmental Group, Scottish Centre for Infection and Environmental Health 2002. Guidelines for public health management of meningococcal disease in the UK. Commun Dis Public Health 5: 187-204.

Razzaq N, Riordan T, McNinch AW, Daneshmend TK 1998. A possible secondary case of pneumococcal meningitis. J Infect 37: 290-291.

Rebelo MC, Boente RF, Matos JA, Hofer CB, Barroso DE 2006. Assessment of a two-step nucleic acid amplification assay for detection of Neisseria meningitidis followed by capsular genogrouping. Mem Inst Oswaldo Cruz 101: 809-813.

Riordan FA 2001. Improving promptness of antibiotic treatment in meningococcal disease. Emerg Med J 18: 162-163.

Stephens DS 2007. Conquering the meningococcus. FEMS Microbiol Rev 31: 3-14.

Stoker NG 1991. The polymerase chain reaction and infectious diseases: hopes and realities. Trans R Soc Trop Med Hyg 84: 755-756, 758.

Taha MK 2000. Simultaneous Approach for Nonculture PCR-Based Identification and Serogroup Prediction of Neisseria meningitidis. J Clin Microbiol 38: 855-857.

Taha MK, Alonso JM, Cafferkey M, Caugant DA, Clarke SC, Diggle MA, Fox A, Frosch M, Gray SJ, Guiver M, Heuberger S, Kalmusova J, Kesanopoulos K, Klem AM, Kriz P, Marsh J, Mölling P, Murphy K, Olcén P, Sanou O, Tzanakaki G, Vogel U 2005. Interlaboratory comparison of PCR-based identification and genogrouping of Neisseria meningitidis. J Clin Microbiol 43: 144-149.

Taha MK, Olcén P 2004. Molecular genetic methods in diagnosis and direct characterization of acute bacterial central nervous system infections. APMIS 112: 753-770.

van Ketel RJ, de Wever B, van Alphen L 1990. Detection of Haemophilus influenzae in cerebrospinal fluids by polymerase chain reaction DNA amplification. J Med Microbiol 33: 271-276.

WHO - World Health Organization 1998. Control of epidemic meningococcal disease. Geneva, 84 pp. Available from: http://www. who.int/emc.

Wylie PA, Stevens D, Drake W III, Stuart J, Cartwright K 1997. Epidemiology and clinical management of meningococcal disease in west Gloucestershire: retrospective, population based study. BMJ 315: 774-779. 